


\title{
Impacto del IVA en la metodología de formulación y evaluación de proyectos de inversión ${ }^{1}$
}

Impact of VAT on the methodology of formulation

and evaluation of investment projects

\author{
Juan Gallardo Cervantes \\ Facultad de Economía de la unam (México) \\ Correo electrónico: gallardocervantesjuan@yahoo.co.uk
}

(Recibido: 19/04/2018. Aceptado para publicación: 26/02/2019)

DOI: 10.22201/fe.24484962e.2018.v7n13.a4

\section{ANTECEDENTES}

omo resultado de una investigación realizada en el primer trimestre de 2017 en el acervo bibliográfico de la Biblioteca "Enrique González Aparicio" de la Facultad de Economía de la Universidad Nacional Autónoma de México (UNAM) se encontró que actualmente ninguno de los libros de texto sobre formulación y evaluación de proyectos de inversión incluye al Impuesto al Valor Agregado (IVA) como parte de los aspectos financieros, especialmente en el tratamiento y análisis del presupuesto de inversiones y reinversiones. Consecuentemente, también se encontró que los diversos trabajos de investigación (tesis o tesinas) sobre proyectos de inversión presentados en exámenes profesionales, tanto de la Facultad de Economía como de otras Facultades de la UNAM, omiten la inclusión del IVA dentro del presupuesto de inversiones sin tener en cuenta los efectos fiscales que tal exclusión tiene en el desarrollo de los aspectos financieros y, en especial, en el cálculo de los indicadores de evaluación de proyectos.

En octubre de 2017 se presentó una ponencia en el XXVII Coloquio Mexicano de Economía Matemática y Econometríaª sobre la omisión del iva y otras tres omisiones que hay

1 Este trabajo fue financiado con recursos del Programa de Apoyo a Proyectos para la Innovación y Mejoramiento de la Enseñanza (PAPIME) que coordina la Dirección General de Asuntos del Personal Académico (DGAPA) de la unAM, mediante el proyecto PE313418 "Diseño y elaboración de Manual de Evaluación Económica y Financiera de Proyectos de Inversión Bajo Condiciones de Certeza y Bajo Condiciones de Riesgo".

2 "Avance de investigación sobre la inclusión de cuatro temas que actualmente se omiten en la metodología de formulación y evaluación de proyectos de inversión", XXVII Coloquio Mexicano de Economía Matemática y Econometría, Escuela 
en la enseñanza de la metodología para la formulación y evaluación de proyectos de inversión, en cuya presentación se lanzó un reto a los colegas asistentes en el sentido de analizar cualesquiera de las cuatro omisiones con el objeto de verificar si éstas eran realmente significativas o no, es decir, si valía la pena considerarlas y rehacer los aspectos financieros. La conclusión fue que sólo valdría la pena hacer los análisis si las variables e indicadores financieros resultaran significativamente diferentes en un valor mayor o igual a $5 \%$.

Este reto se retoma en el presente documento mediante el desarrollo de dos alternativas de evaluación de un proyecto de inversión: la primera se refiere a la omisión del IVA y la segunda a su inclusión como parte de los aspectos financieros de un proyecto, mostrando las diferencias entre ambos casos y señalando la relevancia o no de la variabilidad de los indicadores financieros para tratar de validar la siguiente hipótesis:

Hipótesis. La variabilidad de cada uno de los aspectos financieros, así como los diferentes indicadores de evaluación de un proyecto, ocurren en todos los casos y siempre es igual o mayor a $5 \%$.

El objetivo de este documento es resaltar la importancia fiscal y financiera que tiene el desglose del IVA en la adquisición de los activos que conforman el presupuesto de inversiones y reinversiones de un proyecto de inversión, así como hacer notar los efectos que tiene su exclusión en cada uno de los

Superior de Economía, Instituto Politécnico Nacional, 9-13 de octubre de 2017. Véase J. Gallardo Cervantes, "Cuatro omisiones en la enseñanza de Formulación y Evaluación de Proyectos de Inversión", Ciencia Económica, 6(11), pp 132-147. DOI: 10.22201/fe.24484962e.2018.v6n11.a5. temas que tratan los aspectos financieros de un proyecto de inversión.

\section{INTRODUCCIÓN}

De acuerdo con la Ley del Impuesto al Valor Agregado vigente, la enajenación de bienes y servicios en México requiere que en la factura que ampara la transacción económica se desglose en forma expresa y por separado el IVA que fue objeto de la transacción, ya que de no hacerse en los términos que señala la Ley, el bien o servicio adquirido no tiene validez fiscal y el importe pagado por el activo no formará parte de los estados financieros. Esto es, su depreciación y/o amortización no será deducible de los ingresos (Artículo 10). ${ }^{3}$

Cuando se adquiere un bien o un activo sujeto al IVA, el importe pagado debe dividirse entre 1.16 (uno más la tasa del IVA); el cociente resultante es el valor del activo para fines fiscales y el resto (el 16\%) representa el IVA que se paga en la compra del bien o servicio (Artículo $1^{\circ}$ ). Este impuesto deberá acreditarse en las declaraciones mensuales del IVA y se recuperará cuando la firma enajene bienes y servicios por los que cobra dicho impuesto.

Considere como ejemplo una empresa que adquiere una maquinaria a crédito, cuyo precio es de $\$ 464000.00$, mismo que acuerda pagar a un año, sin intereses de por medio, mediante la firma de un pagaré. De acuerdo con la Ley del Impuesto al Valor Agregado, la factura deberá desglosar de manera expresa y por separado el importe de la maquinaria, así como el IVA pagado. Lo anterior implica que el importe asentado por el total

\footnotetext{
3 Ley del Impuesto al Valor Agregado, 2016. [en línea] México: Cámara de Diputados del H. Congreso de la Unión. Disponible en: < http://www.diputados.gob.mx/ LeyesBiblio/pdf/77_301116.pdf >
} 
de la transacción ( $\$ 464000.00$ ) se divida por 1.16 , lo que da como resultado el valor real de la maquinaria desde el punto de vista fiscal, es decir, \$400 000.00. Asimismo, llevará el importe pagado por concepto del IVA, esto es, el 16\% de los $\$ 400$ 000.00. De esta manera, la factura tendrá los siguientes renglones:

\begin{tabular}{|lr|}
\hline Venta de la maquinaria & $\$ 400000.00$ \\
IVA (16\%) & $\$ 64000.00$ \\
$\begin{array}{l}\text { Importe total de la } \\
\text { transacción }\end{array}$ & $\$ 464000.00$ \\
\hline
\end{tabular}

Cuando el contador de la empresa recibe la factura hace los siguientes asientos contables que formarán parte del Balance General de dicha organización.

Primero hace un asiento en el activo circulante para registrar $\$ 64000.00$ del IVA que se pagó y que podrá acreditar posteriormente en la declaración mensual de la empresa. Luego efectúa un asiento en el activo fijo en el concepto de Maquinaria y equipo de proceso por $\$ 400$ 000.00. Finalmente, como la transacción fue a crédito y éste es por un año, el contador registra la deuda de $\$ 464000.00$ como un pasivo a corto plazo. De manera que los tres asientos estarán en balance, como puede apreciarse en el siguiente cuadro: elaboración de los aspectos financieros como en los indicadores de evaluación del proyecto, que son el objeto de este documento y que serán analizados profusa y puntualmente en el resto del mismo.

Por otra parte, además de lo dicho hasta este punto, desde una óptica financiera, la importancia de desglosar el IVA radica en que las diferentes líneas de crédito, así como las reglas de operación que rigen a los intermediarios financieros, no consideran financiable ningún tipo de impuestos. En consecuencia, el cálculo del costo ponderado de capital, que se emplea como tasa de descuento para evaluar proyectos, también puede ser erróneo y, por lo mismo, el resultado de la evaluación de un proyecto contendrá errores que impedirán una eficiente toma de decisiones sobre el presupuesto del capital.

Dado que en las diferentes universidades, particularmente en las Facultades donde se enseña una metodología que norma la manera en la que se debe realizar la formulación y evaluación de proyectos de inversión, es de suma importancia que se revise este tópico sobre los efectos que puede tener un correcto tratamiento del IVA en la evaluación de proyectos, ya que su omisión o exclusión llevaría a una serie de errores que no sólo se concatenan, sino que sumados

ASIENTOS CONTABLES DENTRO DEL BALANCE GENERAL

\begin{tabular}{ll|l|}
\multicolumn{1}{c|}{ Activos } & \multicolumn{2}{c}{ Pasivos } \\
\hline $\begin{array}{l}\text { Activos circulantes } \\
\text { IVA acreditable }\end{array}$ & Pasivo a corto plazo & 464000.00 \\
$\begin{array}{l}\text { Activos fijos } \\
\text { Maquinaria y equipo de proceso }\end{array}$ & 400000.00 & \\
\hline
\end{tabular}

Además de los problemas fiscales descritos anteriormente, si no se desglosa el IVA del importe pagado por los activos, entonces se desencadena una serie de efectos tanto en la pueden representar el rechazo de buenos proyectos o la aceptación de proyectos inadecuados, en este documento se revisarán los resultados del análisis de dos alternativas de 
evaluación de un mismo proyecto (véase el Anexo A), cuyos elementos para cada una de ellas son los que se exponen a continuación:

- El importe de las inversiones iniciales en la etapa de instalación del proyecto.

- El flujo y calendario de inversiones y reinversiones durante el periodo operativo.

- La determinación de los gastos virtuales.

- La determinación del valor residual de los activos en el periodo de liquidación.

- La determinación de los gastos de operación.

- El cálculo del punto de equilibrio operativo.

- La determinación del Estado de Resultados.

- La determinación de la utilidad de operación.

- La determinación del Impuesto Sobre la Renta (ISR).

- La determinación de la Participación de los Trabajadores en las Utilidades (PTU).

- La determinación de las utilidades netas fiscales.

- La determinación del Estado de Fuentes y Usos del Efectivo.

- La determinación de los flujos de efectivo para evaluar el proyecto.

- El cálculo de indicadores financieros de rentabilidad del proyecto:

- el valor actual neto (VAN),

- el periodo de recuperación del capital (PRC),

- la relación de beneficio/costo (B/C), y

- la tasa interna de rentabilidad (TIR).

\section{MÉTODO DE ANÁLISIS}

Con el objeto de ser didácticos y simplificar la exposición, haremos la evaluación de un proyecto de inversión para dos alternativas (véase el Anexo A). La primera la denominaremos "SIN", misma que no toma en cuenta la diferenciación y desglose del IVA, y la segunda la llamaremos "CON", la cual se ajusta a la Ley del Impuesto al Valor Agregado vigente $\mathrm{y}$, por tanto, considera que sí debe desglosarse el IVA y tratarse separadamente del importe de los activos.

El análisis se hará para cada uno de los aspectos planteados anteriormente, $y$ en cada uno de ellos se realizará una evaluación sobre la variabilidad de los resultados que arroje el análisis de cada alternativa. En cada caso se concluirá si dicha variabilidad es o no significativa o importante y si vale la pena o no realizar los ajustes planteados. El criterio para decidir si la variación es significativa será que ésta sea mayor o igual a $5 \%$.

Dado que en algunos casos la variabilidad será a favor del desglose del Iva y en otros a favor de no desglosarlo, se sugiere que la decisión final se base tomando en cuenta que en un proyecto la información está concatenada y sus efectos son acumulativos; por lo tanto, quien lea este documento deberá decidir en función no de los resultados parciales (de cada aspecto), sino de aquellos indicadores financieros que se originan en los flujos de efectivo, los cuales servirán como criterios de evaluación sobre la viabilidad económicofinanciera de un proyecto de inversión. ${ }^{4}$

\section{ANÁLISIS DEL IMPORTE DE LA INVERSIÓN INICIAL}

De aquí es, precisamente, de donde parte toda la problemática del desglose del IVA y sus repercusiones en la evaluación de un proyecto. En el cuadro 1 se pueden observar los diferentes activos en los que se invierten

4 Entre otros, el VAN, la B/C, el PRC y la TIR. 
los recursos financieros aportados por los socios (capital social), la información se presenta sin desglosar el IVA, la alternativa "SIN", tal como se hace y se enseña actualmente en las aulas y los libros de texto. La inversión inicial total asciende a 35686.00 miles de pesos (mdp), mismos que se concentran en las inversiones fijas (59.3\%) y en el capital de trabajo (39\%).

Por su parte, el cuadro 2 presenta los datos de la alternativa "CON" que aun cuando registra el mismo importe que se eroga en la adquisición de los activos (35 $686.00 \mathrm{mdp}$ ), el importe que fiscalmente es depreciable resulta sensiblemente menor, pues al desglosar el IVA (4 $456.00 \mathrm{mdp}$ ) el importe depreciable ${ }^{5}$ asciende a sólo $31230.00 \mathrm{mdp}$, esto es, se

5 Es decir, el importe que se emplea como base para aplicar los distintos porcentajes de depreciación o amortización anuales señalados en la Ley del Impuesto Sobre la Renta.

\section{CUADRO 1 \\ INVERSIÓNTOTAL REQUERIDA PARA EL INICIO DE OPERACIONES DE LA ALTERNATIVA "SIN" (MILES DE PESOS)}

\begin{tabular}{|l|r|}
\hline Conceptos de inversión & $\begin{array}{c}\text { Importe pagado } \\
\text { por los activos }\end{array}$ \\
\hline Inversión fija & 21186.00 \\
Terreno & 3380.00 \\
Edificio & 7540.00 \\
Equipo de proceso & 6264.00 \\
Equipo de transporte & 2900.00 \\
Equipo de computo & 232.00 \\
Equipo de oficina & 174.00 \\
Equipo de laboratorio & 696.00 \\
Inversión diferida & 580.00 \\
Capital de trabajo & 13920.00 \\
Inversión total inicial & 35686.00 \\
\hline
\end{tabular}

\section{CUADRO 2}

INVERSIÓNTOTAL REQUERIDA PARA EL INICIO DE OPERACIONES DE LA ALTERNATIVA “CON” (MILES DE PESOS)

\begin{tabular}{|l|r|r|r|} 
Conceptos de inversión & $\begin{array}{c}\text { Importe } \\
\text { depreciable }\end{array}$ & \multicolumn{1}{c|}{$\begin{array}{c}\text { IVA } \\
\text { pagado }\end{array}$} & $\begin{array}{c}\text { Importe pagado por } \\
\text { los activos }\end{array}$ \\
\hline Inversión fija & 18730.00 & 2456.00 & 21186.00 \\
Terreno & 3380.00 & 0.00 & 3380.00 \\
Edificio & 6500.00 & 1040.00 & 7540.00 \\
Equipo de proceso & 5400.00 & 864.00 & 6264.00 \\
Equipo de transporte & 2500.00 & 400.00 & 2900.00 \\
Equipo de computo & 200.00 & 32.00 & 232.00 \\
Equipo de oficina & 150.00 & 24.00 & 174.00 \\
Equipo de laboratorio & 600.00 & 96.00 & 696.00 \\
Inversión diferida & 500.00 & 80.00 & 580.00 \\
Capital de trabajo & 12000.00 & 1920.00 & 13920.00 \\
Inversión total inicial & 31230.00 & 4456.00 & 35686.00 \\
\hline
\end{tabular}


reduce en $12.48 \%$, lo cual, de acuerdo con el criterio establecido, representa una variabilidad significativa. En este sentido, se hace prioritario el desglose del IVA.

\subsection{Análisis del flujo de inversiones y reinversiones}

Además de la inversión inicial, durante el periodo operativo será necesario reemplazar aquellos activos fijos cuya vida útil sea menor que el periodo operativo (equipos de cómputo y transporte). Asimismo, el capital de trabajo variará en función de la tasa de crecimiento del pronóstico de ventas, es decir, si el pronóstico de ventas se incrementa anualmente, lo mismo hará el capital de trabajo. Los importes para cada año se calcularon de acuerdo con los señalamientos que registra el Anexo A.

Para el caso de la alternativa "SIN", el cuadro 3 muestra que, además de la inversión inicial para el arranque de las operaciones, serán necesarios desembolsos adicionales por $5359.10 \mathrm{mdp}$, mismos que se requerirán en cantidades anuales que van de $\mathbf{5 2 6 . 2 0}$ mdp en el segundo año a 3488.10 mdp en el último año de operación.

Asimismo, en el periodo de liquidación (año 6) se desinvierte enajenando todos los activos de acuerdo con su valor en libros, las cifras o importes obtenidos representan una entrada de efectivo a diferencia de las demás cantidades que hay en los periodos de instalación y operación (años 0 al 5), las cuales representan salidas de efectivo que los accionistas habrán de cubrir con nuevas aportaciones de capital o bien mediante las utilidades generadas durante el periodo de operación que aún no se han distribuido.

El cálculo del valor residual de los activos en el año 6 se hizo teniendo en cuenta los siguientes tres aspectos:

1. Los activos fijos tendrán valor residual sólo cuando su vida útil exceda al periodo operativo y se calculará contablemente mediante la fórmula del valor en libros $\left(V L_{x}=\right.$ Valor del activo - Depreciación acumulada). El importe de cada concepto se determinó en el cuadro 4 .

2. Los activos diferidos no tienen valor residual, independientemente de que no se hayan amortizado totalmente durante el periodo operativo. Esto es, la parte no recuperada mediante los cargos por amortización realizados durante la operación del proyecto se considera una pérdida y no se registra en ningún estado financiero ni en el flujo de efectivo.

CUADRO 3

FLUJOY CALENDARIO DE INVERSIONES DURANTE EL HORIZONTE DE PLANEACIÓN DE LA ALTERNATIVA “SIN” (MILES DE PESOS)

\begin{tabular}{|c|c|c|c|c|c|c|}
\hline \multirow{2}{*}{ Conceptos de inversión } & \multicolumn{6}{|c|}{ Horizonte de planeación (años) } \\
\hline & 0 & 2 & 3 & 4 & 5 & 6 \\
\hline Inversión fija & 21186.00 & & & 232.00 & 2900.00 & 14954.30 \\
\hline Inversión diferida & 580.00 & & & & & 0.00 \\
\hline Capital de trabajo & 13920.00 & 526.20 & 546.10 & 566.70 & 588.10 & 0.00 \\
\hline Flujo de inversión y reinversión & 35686.00 & 526.20 & 546.10 & 798.70 & 3488.10 & 14954.30 \\
\hline
\end{tabular}


CUADRO 4

CÁLCULO DEL VALOR RESIDUAL DE LAS INVERSIONES AL FINAL DEL PERIODO DE LIQUIDACIÓN DE LA ALTERNATIVA "SIN"

(MILES DE PESOS)

\begin{tabular}{|lrr|r|}
$\begin{array}{l}\text { Conceptos } \\
\text { de inversión }\end{array}$ & \multicolumn{1}{|l|}{ Importe } & \multicolumn{1}{|c|}{ Importe } \\
\hline Terreno & 3380.00 & 3380.00 \\
Edificio & 7540.00 & 5655.00 \\
Equipo de proceso & 6264.00 & 3232.00 \\
Equipo de transporte & 2900.00 & 2175.00 \\
Equipo de computo & 232.00 & 77.30 \\
Equipo de oficina & 174.00 & 87.00 \\
Equipo de laboratorio & 696.00 & 348.00 \\
Valor residual total & & 14954.30 \\
\hline
\end{tabular}

3. En el caso del capital de trabajo no se considera que haya valor de rescate, ya que los diversos inventarios, así como las cuentas por cobrar y por pagar, se recuperan vía los ingresos de cada año.

Finalmente, se puede verificar que la suma de los valores residuales de los activos en el periodo de liquidación (año 6) es exacta- mente el mismo que el valor en libros de la inversión fija. Esto es, 14954.30 mdp, lo que significa que recupera el $41.9 \%$ de la suma que se invirtió para iniciar operaciones.

Por su parte, para la alternativa "CON" el cuadro 5 nos permite observar que, además de la inversión inicial para el arranque de las operaciones, serán necesarios desembolsos adicionales por $5359.10 \mathrm{mdp}$, mismos que se requerirán en cantidades anuales que van de 526.20 mdp en el segundo año a 3488.10 mdp en el último año de operación, es decir, las cifras son idénticas a las de la alternativa "SIN". ¿Qué tiene esto de significativo? Aparentemente nada, pero no adelantemos vísperas y consideremos que para la alternativa "CON" el cuadro 5 nos muestra que el flujo de inversión y reinversión es casi idéntico al de la alternativa "SIN". Esto es, el flujo de inversiones y reinversiones es idéntico en los años cero al cinco y sólo el valor residual de los activos, en el año 6, es diferente en ambas alternativas, siendo de 14954.30 mdp en la alternativa "SIN" y de 13271.70 en la alternativa "CON", esto representa una diferencia de 1 782.60, es decir, una variabilidad significativa de $11.25 \%$. Esto último indica que debiera hacerse el desglose del IVA.

\section{CUADRO 5}

FLUJOY CALENDARIO DE INVERSIONES DURANTE EL HORIZONTE DE PLANEACIÓN DE LA ALTERNATIVA “CON” (MILES DE PESOS)

\begin{tabular}{|lr|r|r|r|r|r|}
\hline \multicolumn{7}{|c|}{ Horizonte de planeación (años) } \\
\hline Conceptos de inversión & $\mathbf{0}$ & $\mathbf{2}$ & $\mathbf{3}$ & $\mathbf{4}$ & $\mathbf{5}$ & $\mathbf{6}$ \\
\hline $\begin{array}{l}\text { Inversión fija } \\
\text { Inversión diferida }\end{array}$ & 18730.00 & & & 200.00 & 2500.00 & 13271.70 \\
Capital de trabajo & 500.00 & & & & & 0.00 \\
IVA pagado & 12000.00 & 453.60 & 470.80 & 488.50 & 507.00 & \\
Flujo de inversión y reinversión & 35686.00 & 526.20 & 546.10 & 798.70 & 3488.10 & 13271.70 \\
\hline
\end{tabular}


Pero más allá de lo hasta aquí mencionado, al incluir de forma expresa y por separado el IVA pagado, cada uno de los demás conceptos de la alternativa "CON" son de menor cuantía que los de la alternativa "SIN", lo cual obliga a plantearnos lo siguiente: si los flujos de salidas de efectivo son casi idénticos en ambas alternativas, ¿qué importancia tiene el desglosar o no el IVA? Bueno, una primera respuesta es que en la alternativa "CON" se recupera más rápido la inversión realizada que en la alternativa "SIN". ¿Cómo es posible esto? Lo que sucede es que mientras en la alternativa "SIN" los flujos de inversión se recuperan exclusivamente mediante la depreciación y amortización de los activos, en la alternativa "CON" la recuperación de estos flujos, además de los cargos virtuales, se hace mediante la acreditación del IVA en las declaraciones de impuestos mensuales.

En efecto, el IVA es un impuesto al consumo que sólo pagan los consumidores finales; las organizaciones lo pagan, pero recuperan el importe del mismo cuando venden sus productos, los cuales están sujetos a este impuesto. Es más, aun cuando el producto a enajenar se haga a una tasa del $0 \%$ del IVA $y$, por tal razón, no se pueda hacer su recuperación al momento de la venta del producto, ésta se hace solicitando a la Secretaría de Hacienda y Crédito Público la devolución del impuesto que se haya pagado, que para fines fiscales se denomina IVA acreditable. La excepción a lo dicho es cuando el producto está exento del pago del IVA, ya que el impuesto pagado pasa a formar parte del costo de los productos y, como cualesquiera costos, se recupera mediante el ingreso, cuando los productos son enajenados.

Respecto al cálculo del valor residual de los activos en el año 6, se hizo exactamente de la misma manera que en la alternativa "SIN", pero en este caso las cifras residuales recuperadas son menores, como se mencionó en párrafos anteriores. El cálculo se hizo teniendo en cuenta los siguientes tres aspectos:

1. Los activos fijos tienen valor residual sólo cuando su vida útil exceda al periodo operativo y se calcula contablemente mediante la fórmula del valor en libros $\left(V l_{x}=\right.$ Valor del activo - Depreciación acumulada). El importe de cada concepto se determinó en el cuadro 6, siendo de $13271.70 \mathrm{mdp}$.

2. Los activos diferidos no tienen valor residual, independientemente de que no se hayan amortizado totalmente durante el periodo operativo. Es decir, la parte no recuperada mediante los cargos por amortización realizados durante la operación del proyecto se considera una pérdida no registrada.

3. En el caso del capital de trabajo no se considera que haya valor de rescate, ya que los diversos inventarios, así como las cuentas por cobrar y por pagar, se recuperan vía los ingresos de cada año.

CUADRO 6

CÁLCULO DEL VALOR RESIDUAL DE LAS INVERSIONES AL FINAL DEL PERIODO DE LIQUIDACIÓN DE LA ALTERNATIVA “CON" (MILES DE PESOS)

\begin{tabular}{|l|r|r|}
\hline $\begin{array}{l}\text { Conceptos } \\
\text { de inversión }\end{array}$ & Importe & \multicolumn{1}{|c|}{ Importe } \\
\hline Terreno & 3380.00 & 3380.00 \\
Edificio & 6500.00 & 4875.00 \\
Equipo de proceso & 5400.00 & 2700.00 \\
Equipo de transporte & 2500.00 & 1875.00 \\
Equipo de computo & 200.00 & 66.7 .00 \\
Equipo de oficina & 150.00 & 75.00 \\
Equipo de laboratorio & 600.00 & 300.00 \\
Valor residual total & & 13271.70 \\
\hline
\end{tabular}


Finalmente, se puede verificar que en la alternativa "CON" la suma de los valores residuales de los activos en el periodo de liquidación (año 6) asciende a 13271.70 mdp, esto es, se recupera casi el $37.3 \%$ de la suma que se invirtió para iniciar operaciones, mientras que en la alternativa "SIN" el porcentaje de recuperación fue de $41.9 \%$. También en este caso se puede observar que la variabilidad entre estos porcentajes es significativa, al ser de $8.9 \%$, cifra mayor al 5\% propuesto como criterio de significancia. Se infiere que el IVA debe desglosarse.

La aseveración acerca de que en la alternativa "CON" se recuperan más rápido los flujos de inversión y reinversión quedará aclarada totalmente cuando se trate el análisis de los gastos virtuales y se tengan las cifras de cada alternativa. Volveremos a este punto en el siguiente análisis.

\subsection{Análisis de los gastos virtuales de los activos}

Los gastos virtuales se refieren a los cargos periódicos que, de acuerdo con las tasas anuales autorizadas por la Ley del Impuesto Sobre la Renta, se hacen bajo el nombre de depreciación (para el caso de los activos fijos, exceptuando el terreno) o amortización (para el caso de los activos intangibles). Dado que estos cargos representan la forma mediante la cual es recuperado el importe invertido en los activos fijos y diferidos, y considerando además que las tasas empleadas para el cálculo son las mismas en los dos tipos de análisis, entonces debe resultar claro que el cargo anual por estos conceptos será siempre mayor ${ }^{6}$ para la alternativa "SIN" que para la alternativa "CON".

En este sentido, el cuadro 7 nos permite observar que mientras el cargo anual por depreciación en la alternativa "SIN" asciende a 2393.33 mdp, en la alternativa "CON" este cargo anual sólo es por $2066.67 \mathrm{mdp}$, es decir, una diferencia de 326.66 mdp anuales.

6 Esto es obvio si se considera que el importe del activo en la alternativa "SIN" siempre será mayor que el de la alternativa "CON", en una cantidad menor o igual a la tasa del IvA considerada. Recuérdese que hay varias tasas del IVA: $20 \%, 16 \%, 0 \%$ y exento.

\section{CUADRO 7}

CARGO ANUAL POR DEPRECIACIONES DE ACTIVOS FIJOS (MILES DE PESOS)

\begin{tabular}{|lr|r|r|r|r|} 
& \multicolumn{2}{c|}{$\begin{array}{c}\text { Valor depreciable } \\
\text { del activo }\end{array}$} & $\begin{array}{r}\text { Tasa fiscal anual } \\
\text { de depreciación (\%) }\end{array}$ & \multicolumn{2}{c|}{ Cargo anual } \\
\hline “SIN" & “CON" & & “SIN" & "CON" \\
\hline Terreno & 3380.00 & 338.00 & 0.00 & 0.00 & 0.00 \\
Edificio & 754.00 & 650.00 & 5.00 & 37.00 & 325.00 \\
Equipo de transporte & 626.00 & 540.00 & 25.00 & 156.00 & 1350.00 \\
Equipo de proceso & 290.00 & 250.00 & 10.00 & 29.00 & 250.00 \\
Equipo de cómputo & 23.00 & 20.00 & 33.33 & 73.33 & 66.67 \\
Equipo oficina & 17.00 & 15.00 & 10.00 & 17.40 & 15.00 \\
Equipo de laboratorio & 69.00 & 60.00 & 10.00 & 69.60 & 60.00 \\
Cargo anual por depreciación & & & & 2393.33 & 2066.67 \\
\hline
\end{tabular}


Lo señalado respecto a las depreciaciones de los activos fijos también puede afirmarse acerca de las amortizaciones de activos intangibles. En efecto, el cuadro 8 nos muestra que mientras la amortización de la alternativa "SIN" representa un cargo anual por $58 \mathrm{mdp}$, la amortización de la alternativa "CON" sólo llega a $50 \mathrm{mdp}$, esto es, una diferencia de 8 mil pesos anuales.

Si sumamos los cargos anuales derivados de ambos gastos virtuales (depreciación y amortización) tendremos que mientras la alternativa "SIN" tiene un cargo por 2451.33 mdp, en la alternativa "CON" dicho gasto es por $2116.67 \mathrm{mdp}$, lo que representa una diferencia de $334.66 \mathrm{mdp}$ anuales. Esta diferencia representa un porcentaje de variabilidad de $13.65 \%$, el cual excede el criterio de 5\%, lo cual sigue sugiriendo que el desglose del IVA en el importe pagado por los activos es significativo y debe tenerse en cuenta.

La conclusión anterior sobre el importe del cargo anual por gastos virtuales a favor de la alternativa "SIN" podría parecer contradictoria con la afirmación que hicimos acerca de la rapidez con la cual se recuperan los flujos de inversiones y reinversiones. Por lo tanto, para salir de dudas y evitar posibles confusiones, haremos los siguientes cuadros para ver la manera en la que cada alternativa permite recuperar el flujo de inversiones, posteriormente compararemos las cifras y concluiremos qué alternativa permite una recuperación más rápida de la inversión.

En la alternativa "SIN" (véase el cuadro 9) la recuperación de la inversión se hace

\section{CUADRO 8}

CARGO ANUAL POR AMORTIZACIÓN DE ACTIVOS INTANGIBLES (MILES DE PESOS)

\begin{tabular}{|lc|c|c|c|c|} 
& \multicolumn{2}{c|}{$\begin{array}{c}\text { Valor amortizable } \\
\text { del activo }\end{array}$} & $\begin{array}{c}\text { Tasa fiscal anual } \\
\text { de amortización (\%) }\end{array}$ & \multicolumn{2}{c|}{ Cargo anual } \\
\cline { 2 - 6 } & “SIN" & “CON" & & “SIN" & “CON" \\
\hline Inversión diferida & 580.00 & 500.00 & 10.00 & 58.00 & 50.00 \\
Cargo anual por amortización & & & 58.00 & 50.00 \\
\hline
\end{tabular}

\section{CUADRO 9}

RECUPERACIÓN DEL FLUJO DE INVERSIONESY REINVERSIONES DE LA ALTERNATIVA “SIN” (MILES DE PESOS)

\begin{tabular}{|l|c|c|c|c|}
\hline $\begin{array}{l}\text { Periodo operativo } \\
\text { (años) }\end{array}$ & $\begin{array}{c}\text { Flujo de } \\
\text { inversiones y } \\
\text { reinversiones }\end{array}$ & $\begin{array}{c}\text { Flujo de inversiones } \\
\text { y reinversiones } \\
\text { acumulado }\end{array}$ & $\begin{array}{c}\text { Recuperación } \\
\text { mediante los gastos } \\
\text { virtuales acumulados }\end{array}$ & $\begin{array}{c}\text { Cantidad } \\
\text { por recuperar }\end{array}$ \\
\hline 0 & 35686.00 & 35686.00 & 0.00 & 35686.00 \\
1 & 35686.00 & 2451.33 & 33234.67 \\
2 & 526.20 & 36212.20 & 4786.66 & 31309.54 \\
\hline 4 & 546.10 & 36758.30 & 7179.99 & 29404.31 \\
5 & 798.70 & 37557.00 & 9573.32 & 27751.68 \\
\hline
\end{tabular}


exclusivamente mediante los gastos virtuales (2 451.33 mdp anuales). Obsérvese que para cuando termina el periodo operativo (año 5) aún quedan 28788.45 mdp por recuperar.

El procedimiento para calcular la cantidad por recuperar de cada año fue el siguiente. Se sumó la reinversión anual de ese mismo año a la cantidad por recuperar del año anterior, suma a la que se le restó el cargo anual del gasto virtual, el cual es constante para los cinco años de operación del proyecto.

Como ejemplo, se calculó la cantidad por recuperar del cuarto año:

- Reinversión: 798.70 mdp.

- Cantidad por recuperar del año anterior: $29404.31 \mathrm{mdp}$.

- Gastos virtuales: 2451.33 mdp.

- Cantidad a recuperar: $29404.31+798.70$ $-2451.33=27751.68 \mathrm{mdp}$.

A diferencia de la alternativa "SIN", cuando se desglosa el iva en la alternativa "CON" (véase el cuadro 10) la recuperación de la inversión se hace, además de los gastos virtuales (2 $116.67 \mathrm{mdp}$ anuales), con el IVA que se acredita cada periodo y el cual se paga. Nótese que para cuando termina el periodo operativo (año 5) aún quedan 25266.55 mdp por recuperar.

El procedimiento para calcular la cantidad por recuperar de cada año fue el siguiente. Se sumó la reinversión anual de ese mismo año a la cantidad por recuperar del año anterior, suma a la que se le restó el IVA y el cargo anual del gasto virtual, el cual es constante para los cinco años de operación del proyecto.

Como ejemplo, se calculó la cantidad por recuperar del cuarto año:

- Reinversión: 798.70 mdp.

- Cantidad por recuperar del año anterior: 25804.39 mdp.

- IVA acreditable: $110.20 \mathrm{mdp}$.

- Gastos virtuales: 2116.67 mdp.

- Cantidad a recuperar: $798.70+25804.39$ $-(110.20+2451.33)=24376.22 \mathrm{mdp}$.

Finalmente, mediante la comparación absoluta y relativa de la recuperación de los flujos de inversión y reinversión en cada alternativa, el cuadro 11 nos permite concluir que para todos y cada uno de los años la alternativa "CON" es la que recuperara más rápido la inversión realizada. En efecto,

CUADRO 10

RECUPERACIÓN DEL FLUJO DE INVERSIONESY REINVERSIONES

DE LA ALTERNATIVA “CON" (MILES DE PESOS)

\begin{tabular}{|c|c|c|c|c|c|}
\hline $\begin{array}{l}\text { Periodo operativo } \\
\text { (años) }\end{array}$ & $\begin{array}{r}\text { Flujo de in } \\
\text { y reinve } \\
\text { acum }\end{array}$ & $\begin{array}{l}\text { versiones } \\
\text { rsiones } \\
\text { ulado }\end{array}$ & $\begin{array}{l}\text { Recuperación } \\
\text { mediante el IVA } \\
\text { acreditado }\end{array}$ & $\begin{array}{c}\text { Recuperación } \\
\text { mediante los gastos } \\
\text { virtuales acumulados }\end{array}$ & $\begin{array}{l}\text { Cantidad por } \\
\text { recuperar }\end{array}$ \\
\hline 0 & 35686.00 & 35686.00 & 4456.00 & 0.00 & 31230.00 \\
\hline 1 & & 35686.00 & & 2116.67 & 29113.33 \\
\hline 2 & 526.20 & 36212.20 & 72.60 & 4233.34 & 27450.26 \\
\hline 3 & 546.10 & 36758.30 & 75.30 & 6350.10 & 25804.39 \\
\hline 4 & 798.70 & 37557.00 & 110.20 & 8466.68 & 24376.22 \\
\hline 5 & 3488.10 & 41045.10 & 481.10 & 10583.35 & 25266.55 \\
\hline
\end{tabular}


CUADRO 11

COMPARATIVO DE LA RECUPERACIÓN DEL FLUJO DE INVERSIONES

Y REINVERSIONES DE AMBAS ALTERNATIVAS (MILES DE PESOS)

\begin{tabular}{|l|c|c|c|c|}
$\begin{array}{l}\text { Periodo operativo } \\
\text { (años) }\end{array}$ & $\begin{array}{c}\text { Cantidad por recuperar } \\
\text { alternativa "SIN" }\end{array}$ & $\begin{array}{c}\text { Cantidad por recuperar } \\
\text { alternativa "CON" }\end{array}$ & $\begin{array}{c}\text { Diferencia } \\
\text { absoluta }\end{array}$ & $\begin{array}{c}\text { Porcentaje de } \\
\text { variación (\%) }\end{array}$ \\
\hline 0 & 35686.00 & 31230.00 & 4456.00 & 12.48 \\
1 & 33234.67 & 29113.33 & 4121.34 & 12.40 \\
2 & 31309.54 & 27450.26 & 3859.28 & 12.32 \\
3 & 29404.31 & 25804.39 & 3599.92 & 12.24 \\
4 & 27751.68 & 24376.22 & 3375.46 & 12.16 \\
\hline 5 & 28788.45 & 25266.55 & 3521.90 & 12.23 \\
\hline
\end{tabular}

como se puede apreciar en el cuadro referido, año con año la diferencia absoluta favorece a la alternativa "CON" y aun cuando ésta va decreciendo, de 4456.00 mdp en el año cero a $3521.90 \mathrm{mdp}$ en el año cinco, se puede apreciar que en cualquier año la diferencia relativa es, en todos los casos, superior a $12 \%$, lo que nos lleva a concluir que también en este análisis la variabilidad es mayor a 5\% y significativa. Razón suficiente para concluir que el desglose del IVA debe ser tenido en cuenta.

\subsection{Análisis de los gastos de operación}

En los proyectos de inversión los gastos de operación suelen dividirse en dos grupos. El primero referido a los gastos que se erogan en efectivo en las distintas funciones sustantivas de la empresa (Producción, administración y comercialización $\left.{ }^{7}\right)$, mientras que en el segundo grupo se encuentran los

\footnotetext{
7 Como sueldos, salarios, prestaciones sociales, energéticos, rentas, mantenimiento preventivo y correctivo, seguros, teléfono, etcétera.
}

gastos virtuales, ${ }^{8}$ de los cuales hemos hablado en el punto anterior. Y si asumimos que los gastos erogados en efectivo son los mismos para cada alternativa (pues no tienen por qué ser diferentes), entonces tendremos que admitir que el comportamiento del gasto de operación total está en función de los gastos virtuales.

De acuerdo con la información que provee el Anexo A, los gastos de operación erogados en efectivo, aunque son más o menos fijos, pueden, pero no lo hacen de manera proporcional ni en función del nivel de actividad que implica el desarrollo del pronóstico de ventas (que en este caso es creciente). Por otra parte, dicha variación puede darse sólo en algunos rubros, pero no en todos, tal como se muestra en el cuadro 12 .

8 Aunque se dice virtuales, estos gastos son reales y derivan del desgaste de los activos, el cual puede ser causado tanto por el uso de los activos como por su obsolescencia u otro factor. Cuando se dice virtual se hace con la finalidad de diferenciarlos de los que son erogados en efectivo, es decir, de los gastos que sí representan un desembolso de efectivo, mientras que los gastos virtuales son sólo asientos contables que se registran en los libros de contabilidad de la empresa. 
CUADRO 12

\section{GASTO DE OPERACIÓN BASE PARA 10 MILTONELADAS Y GASTO INCREMENTAL POR CADA} 500 TONELADAS PRODUCIDAS POR ARRIBA DE 10 MILTONELADAS (MILES DE PESOS)

\begin{tabular}{|l|r|c|}
\hline Conceptos del gasto de operación & $\begin{array}{c}\text { Gasto erogable anual para } \\
\mathbf{1 0} \text { mil toneladas }\end{array}$ & $\begin{array}{c}\text { Gasto incremental por cada } \\
\mathbf{5 0 0} \begin{array}{c}\text { toneladas anuales } \\
\text { adicionales }\end{array}\end{array}$ \\
\hline Sueldos, salarios y honorarios & $\mathbf{3} 896 \mathbf{2 7 0 . 0 0}$ & $\mathbf{4 5 7} 725.00$ \\
Combustibles y lubricantes & 129350.00 & 9315.00 \\
Energéticos & 67890.00 & 1145.00 \\
Agua potable y aditivos para agua & 6000.00 & 90.00 \\
Mantenimiento preventivo & 76250.00 & 7260.00 \\
Mantenimiento correctivo & 12100.00 & 1145.00 \\
Seguros diversos para riesgos & 45890.00 & 0.00 \\
Gastos generales de fabricación & 6500.00 & 0.00 \\
Teléfono, fax, télex y correo & 9500.00 & 0.00 \\
Gastos generales de administración & 1750.00 & 0.00 \\
Fletes, acarreos y paquetería & 10000.00 & 200.00 \\
Teléfono, fax, télex, correo & 15000.00 & 100.00 \\
Viáticos y representación & 23000.00 & 200.00 \\
Seguros diversos para riesgos & 29000.00 & 0.00 \\
Gastos generales de ventas & 6000.00 & 0.00 \\
\hline
\end{tabular}

Los diferentes conceptos mostrados en el cuadro 12 se calcularon para una producción modular base de 10 mil toneladas anuales. Para esa cantidad, el gasto de operación erogable es de 4334.50 mdp anuales, y dado que el pronóstico de ventas es al alza se ha calculado un gasto incremental por cada 500 toneladas de producción adicional. Este gasto incremental es por cada 500 toneladas o fracción de éstas, así que si el aumento en la producción se sitúa en 678 toneladas, en realidad se supondrá dos veces 500 toneladas, así que el gasto incremental para 678 toneladas será el mismo que para 1000 . De esta manera, el pronóstico de ventas será el eje mediante el cual se determina el gasto erogable anual. Como puede verse en el cuadro 13, este gasto comienza en 5864.50 mdp en el año 1 y termina en 7394.50 mdp en el año 5.

Es conveniente notar que este gasto de operación erogable en efectivo es el mismo para cualesquiera de ambas alternativas.

Para terminar con este tema, es necesario sumar al gasto erogable el gasto virtual a fin de obtener el gasto de operación total anual que se registra en el cuadro 14, en el cual se nota que para todos los años el gasto de la alternativa "SIN" es mayor que el de la alternativa "CON", lo cual se debe a que los 
CUADRO 13

DETERMINACIÓN DEL GASTO DE OPERACIÓN EROGABLE ANUAL PARA AMBAS ALTERNATIVAS (MILES DE PESOS)

\begin{tabular}{|l|c|c|c|c|c|}
$\begin{array}{l}\text { Periodo operativo } \\
\text { (años) }\end{array}$ & $\begin{array}{c}\text { Volumen de } \\
\text { ventas } \\
\text { (toneladas) }\end{array}$ & $\begin{array}{c}\text { Producción } \\
\text { adicional } \\
\text { (toneladas) }\end{array}$ & $\begin{array}{c}\text { Número de } \\
\text { veces } 500 \\
\text { toneladas }\end{array}$ & $\begin{array}{c}\text { Gasto } \\
\text { adicional }\end{array}$ & $\begin{array}{c}\text { Gasto de } \\
\text { operación } \\
\text { total }\end{array}$ \\
\hline 1 & 11857 & 1857 & 4 & 1530.00 & 5864.50 \\
3 & 12305 & 2305 & 5 & 1912.50 & 6247.00 \\
4 & 12770 & 2770 & 6 & 2295.00 & 6629.50 \\
5 & 13253 & 3253 & 7 & 2677.50 & 7012.00 \\
\hline
\end{tabular}

CUADRO 14

DETERMINACIÓN DEL GASTO DE OPERACIÓN ANUAL PARA CADA ALTERNATIVA (MILES DE PESOS)

\begin{tabular}{|lc|c|c|c|c|c|}
\hline $\begin{array}{l}\text { Periodo operativo } \\
\text { (años) }\end{array}$ & \multicolumn{3}{c}{ Alternativa "SIN" } & \multicolumn{3}{c|}{ Alternativa "CON" } \\
\hline 1 & Efectivo & Virtual & Total & Efectivo & Virtual & Total \\
\hline 2 & 5864.50 & 2451.33 & 8315.83 & 5864.50 & 2116.67 & 7981.17 \\
3 & 6247.00 & 2451.33 & 8698.33 & 6247.00 & 2116.67 & 8363.67 \\
4 & 6629.50 & 2451.33 & 9080.83 & 6629.50 & 2116.67 & 8746.17 \\
5 & 7012.00 & 2451.33 & 9463.33 & 7012.00 & 2116.67 & 9128.67 \\
\hline 7394.50 & 2451.33 & 9845.83 & 7394.50 & 2116.67 & 9511.17 \\
\hline
\end{tabular}

gastos virtuales son mayores en 334.66 mdp anuales. En este caso, la variabilidad siempre será menor a $5 \%$ y tenderá a bajar cuanto más se incremente el gasto erogable en efectivo. ¿Por qué sucede esto? Porque a medida que aumenta el pronóstico de ventas, aumenta el gasto erogable en efectivo, mientras que la diferencia de gastos virtuales entre ambas alternativas se mantiene constante.

Hasta antes del gasto de operación la variabilidad de los factores analizados estaba por arriba del $12 \%$ y ahora es menor a $4 \%$, ¿esto contradice todo lo analizado anteriormente? Por supuesto que no. Y no tan sólo no contradice, sino que podría hasta ser muy engañoso debido a que un mayor gasto operativo tendrá repercusiones negativas en la utilidad de operación, el pago del ISR, la PTU de la organización y, sobre todo, en la utilidad neta, los flujos de efectivo y el cálculo de los indicadores de evaluación del proyecto.

\subsection{Análisis de los resultados del punto de equilibrio operativo}

Estamos especificando que el análisis a realizar es sobre el punto de equilibrio operativo porque se ha partido del supuesto de que la estructura financiera para financiar los flujos de inversión y reinversión está formada 
exclusivamente por aportaciones accionarias. En el caso de requerir pasivos financieros con costo, tendríamos que incluir dentro del gasto a los intereses o gastos financieros que derivan de la contratación de pasivos financieros.

El punto de equilibrio se puede definir como el nivel de ingresos que una empresa debe recaudar para no tener pérdidas ni ganancias, y se puede calcular de dos formas:

1. Cuando el punto de equilibrio se refiere a una empresa monoproductora se calcula dividiendo el gasto de operación entre la diferencia del precio y el costo directo:

$$
\begin{gathered}
\text { Punto } \\
\text { de equilibrio }
\end{gathered}=\frac{\text { Gasto de operación total anual }}{\text { Precio }- \text { Costo directo }}
$$

El resultado indicará el número de piezas (metros, toneladas, docenas, etc.) que deberán venderse para que la empresa opere sin pérdidas, pero sin ganancias.

2. Cuando el punto de equilibrio se refiere a una empresa poliproductora se calcula dividiendo el gasto de operación entre el margen por peso vendido, el cual se obtiene de dividir la utilidad bruta entre los ingresos por venta:

$\begin{gathered}\text { Punto } \\ \text { de equilibrio }\end{gathered}=\frac{\text { Gasto de operación total anual }}{\text { Margen por peso vendido }}$

donde:

$$
\begin{gathered}
\text { Margen por } \\
\text { peso vendido }
\end{gathered}=\frac{\text { Utilidad bruta }}{\text { Ingresos por venta }}
$$

En el caso que nos ocupa, el margen por peso vendido en cada una de las alternativas es de 0.33735 , pero el gasto de operación es mayor para la alternativa "SIN"; en consecuencia, el punto de equilibrio de ésta será mayor que el de la alternativa “CON”. ¿Esto es positivo? Es decir, ¿es bueno para una empresa tener un punto de equilibrio mayor o será mejor tener un punto de equilibrio menor?

Para responder a las preguntas anteriores, considere un ejemplo simple, donde dos empresas, A y B, tienen una capacidad instalada de 500 piezas diarias cada una. La empresa A logra su equilibrio vendiendo 375 piezas diarias a un precio de 100 pesos por unidad, mientras que la empresa B logra su equilibrio vendiendo 200 piezas diarias al mismo precio que A. Las utilidades de una empresa comienzan cuando ésta vende por arriba de su punto de equilibrio, y dado que ambas empresas tienen la misma capacidad, entonces A genera utilidades diarias por las 125 piezas que vende por arriba del punto de equilibrio, esto es, crea una utilidad diaria de $125 \times 100=12500$ pesos, mientras que $B$ genera utilidades diarias por las 300 piezas que vende por arriba del punto de equilibrio, es decir, crea una utilidad diaria de $300 \times 100$ $=30500$ pesos.

A partir de este sencillo ejemplo, no queda duda que la empresa con un menor punto de equilibrio es la mejor. Ahora bien, ¿qué hay acerca de las dos alternativas? Como se puede apreciar en el cuadro 15, la alternativa "CON" genera un menor gasto de operación; por lo tanto, es mejor que la alternativa "SIN". En efecto, en el cuadro se puede notar que el punto de equilibrio en ambas alternativas tiende a incrementarse año con año. Así, mientras que el equilibrio de la alternativa "SIN" se logra con ingresos por ventas que van de 24654.00 mdp para el primer año de operación a 29190.00 mdp en el quinto año, para la alternativa "CON" el equilibrio se logra con ingresos por ventas que van de 23 662.00 mdp en el primer año de operación a 28198.00 mdp en el quinto año. 
CUADRO 15

PUNTO DE EQUILIBRIO ANUAL (INGRESOS POR VENTA EN MILES DE PESOS)

\begin{tabular}{|l|c|c|c|c|}
$\begin{array}{l}\text { Periodo operativo } \\
\text { (años) }\end{array}$ & Alternativa "CON" & Alternativa "SIN" & $\begin{array}{c}\text { Diferencia } \\
\text { absoluta }\end{array}$ & Diferencia (\%) \\
\hline 1 & 24654.00 & 23662.00 & 992.00 & 4.90 \\
2 & 25788.00 & 24796.00 & 992.00 & 4.00 \\
3 & 26922.00 & 25930.00 & 992.00 & 3.80 \\
4 & 28056.00 & 27064.00 & 992.00 & 3.66 \\
5 & 29190.00 & 28198.00 & 992.00 & 3.52 \\
\hline
\end{tabular}

Además del crecimiento del punto de equilibrio en ambas alternativas, resulta importante señalar que el margen por peso vendido en cada una es el mismo, y que la diferencia del gasto de operación total anual entre ambas alternativas es constante $(992.00$ mdp cada año); por consiguiente, la diferencia porcentual que resulta de dividir los $992.00 \mathrm{mdp}$ entre los ingresos de la alternativa "SIN" mostrarán una tasa o porcentaje descendente y menor a 5\%. En efecto, para el primer año la tasa de variabilidad es de $4.9 \%$, la cual desciende año con año para situarse en $3.52 \%$ en el año 5 .

Como se puede observar, en todos los años la variabilidad es menor al $5 \%$ que propusimos como criterio, por lo cual se puede concluir que para el análisis del punto de equilibrio la variabilidad no es significativa, aunque no deja de ser importante y a favor de lo que hemos venido señalando.

\subsection{Análisis del estado de resultados}

El análisis del ISR y de la PTU, así como el de las utilidades netas que genera el proyecto, requiere la elaboración de un Estado de Resultados para cada alternativa, en el cual se incluyan los presupuestos de ingresos y egresos. Tales estados se presentan en los cuadros 16 y 17, de los cuales se obtendrán los indicadores de ISR, PTU y utilidades netas, aunque cada análisis se hará por separado.

\subsection{Análisis del ISR}

Los cálculos del ISR de ambas alternativas se hicieron multiplicando la utilidad de operación por la tasa de $30 \%$ de acuerdo con la Ley del Impuesto Sobre la Renta vigente. En el cuadro 18 se puede observar que el ISR en cualquiera alternativa es creciente durante todo el periodo, notándose siempre que el pago de este impuesto es menor en la alternativa "CON". Es decir, en esta alternativa hay un ahorro global de 502 mdp durante el periodo operativo del proyecto.

Un hecho que no sorprende es que habiendo un mayor gasto de operación en la alternativa "SIN" uno puede afirmar, por lo mismo, que ante una mayor deducibilidad habrá un pago menor del IsR. En efecto, observando el cuadro 18 se puede concluir que durante todos los años la alternativa "SIN" genera un ahorro anual en el pago del ISR por $100.40 \mathrm{mdp}$.

Si dividimos ese ahorro entre el ISR pagado en la alternativa "SIN" obtendremos el porcentaje anual de ahorro para este impuesto, el cual disminuye paulatinamente a través de los años, siendo de $3.88 \%$ en el primer año y de apenas $3.43 \%$ en el quinto año. La 
CUADRO 16

ESTADO DE RESULTADOS DE LA ALTERNATIVA “SIN" (MILES DE PESOS)

\begin{tabular}{|l|r|r|rr|r}
\hline Conceptos de ingresos o egresos & Año 1 & Año 2 & Año 3 & Año 4 & Año 5 \\
\hline Ingresos por venta & 49206.60 & 51065.80 & 52995.50 & 55000.00 & 57079.10 \\
Costo de lo vendido & 32606.80 & 33838.80 & 35117.50 & 36445.80 & 37823.50 \\
Utilidad bruta & 16599.80 & 17227.00 & 17878.00 & 18554.20 & 19255.60 \\
Gastos de operación en efectivo & 5864.50 & 6247.00 & 6629.50 & 7012.00 & 7394.50 \\
Gastos virtuales & 2451.30 & 2451.30 & 2451.30 & 2451.30 & 2451.30 \\
Utilidad gravable & 8284.00 & 8528.70 & 8797.20 & 9090.90 & 9409.80 \\
ISR (30\%) & 2485.20 & 2558.60 & 2639.20 & 2727.30 & 2822.90 \\
PTU (10\%) & 828.40 & 852.90 & 879.70 & 909.10 & 941.00 \\
Utilidad neta & 4970.40 & 5117.20 & 5278.30 & 5454.50 & 5645.90
\end{tabular}

CUADRO 17

ESTADO DE RESULTADOS DE LA ALTERNATIVA “CON” (MILES DE PESOS)

\begin{tabular}{|lr|r|r|r|r|}
\hline Conceptos de ingresos o egresos & Año 1 & Año 2 & Año 3 & Año 4 & Año 5 \\
\hline Ingresos por venta & 49206.60 & 51065.80 & 52995.50 & 55000.00 & 57079.10 \\
Costo de lo vendido & 32606.80 & 33838.80 & 35117.50 & 36445.80 & 37823.50 \\
Utilidad bruta & 16599.80 & 17227.00 & 17878.00 & 18554.20 & 19255.60 \\
Gastos de operación en efectivo & 5864.50 & 6247.00 & 6629.50 & 7012.00 & 7394.50 \\
Gastos virtuales & 2116.70 & 2116.70 & 2116.70 & 2116.70 & 2116.70 \\
Utilidad gravable & 8618.60 & 8863.30 & 9131.80 & 9425.50 & 9744.40 \\
ISR (30\%) & 2585.60 & 2659.00 & 2739.50 & 2827.70 & 2923.30 \\
PTU (10\%) & 861.90 & 886.30 & 913.20 & 942.60 & 974.40 \\
Utilidad neta & 5171.20 & 5318.00 & 5479.10 & 5655.30 & 5846.60 \\
\hline
\end{tabular}

\section{CUADRO 18}

COMPARATIVO DEL ISR EN AMBAS ALTERNATIVAS (MILES DE PESOS)

\begin{tabular}{|c|c|c|c|c|}
\hline $\begin{array}{l}\text { Periodo operativo } \\
\text { (años) }\end{array}$ & Alternativa "SIN" & Alternativa "CON" & $\begin{array}{l}\text { Diferencia } \\
\text { absoluta }\end{array}$ & $\begin{array}{c}\text { Diferencia } \\
(\%)\end{array}$ \\
\hline 1 & 2485.20 & 2585.60 & 100.40 & 3.88 \\
\hline 2 & 2558.60 & 2659.00 & 100.40 & 3.78 \\
\hline 3 & 2639.20 & 2739.50 & 100.30 & 3.66 \\
\hline 4 & 2727.30 & 2827.70 & 100.40 & 3.55 \\
\hline 5 & 2822.90 & 2923.30 & 100.40 & 3.43 \\
\hline
\end{tabular}


razón de este decremento consiste en que el ahorro del ISR es constante durante todo el periodo operativo (100.40 mdp), mientras que el ISR a cargo de la alternativa "SIN" es creciente cada año.

En este caso, como en el del gasto de operación, el porcentaje de variación es menor a 5\%; por lo tanto, se puede concluir que al no ser significativa la variabilidad no vale la pena hacer el desglose del IVA, además de que la alternativa "SIN" genera ahorros por 500 mil pesos en el pago del ISR.

\subsection{Análisis de la PTU}

Los cálculos de la PTU en ambas alternativas se hicieron multiplicando la utilidad de operación por la tasa de $10 \%$ de acuerdo con la Ley Federal del Trabajo vigente. En el cuadro 19 se observa que la PTU en cualquiera alternativa es creciente durante todo el periodo, advirtiéndose que año con año el pago de la PTU es menor en la alternativa "SIN". Esto es, en esta alternativa hay un ahorro global de $167.30 \mathrm{mdp}$ durante el periodo operativo del proyecto.

Al igual que en el caso del cálculo del ISR, no sorprende que habiendo un mayor gasto de operación en la alternativa "SIN" se pueda decir que en ella se pagará una menor PTU, lo cual resulta mejor en la alternativa "SIN", ya que es en la que se ahorra este pago.
Las diferentes cantidades de la PTU ahorradas anualmente y divididas entre la PTU pagada en la alternativa "SIN" nos dará el porcentaje de ahorro en este concepto, el cual disminuye gradualmente a través de los años, siendo de 3.88\% en el primer año y de apenas $3.43 \%$ en el quinto año. Ello nos indica, ciertamente, que el comportamiento relativo es idéntico al mostrado por el ISR; por ende, la conclusión es similar, agregando que la alternativa "SIN" supone ahorros de 167.30 mdp en el pago de reparto de utilidades a los trabajadores.

\subsection{Análisis de la utilidad neta}

La utilidad neta se calculó restando de la utilidad de operación la suma del ISR y la PTU; así, la diferencia de utilidad neta anual entre ambas alternativas es constante, dando como resultado $208.80 \mathrm{mdp}$ a favor de la alternativa "CON". Es decir, esta alternativa representa una utilidad neta mayor a la alternativa "SIN", por un importe total de $1043.50 \mathrm{mdp}$ durante los cinco años.

Asimismo, aun si tenemos en cuenta que la alternativa "SIN" es la que genera menor pago del ISR (501.90 mdp) y de la PTU (167.30 mdp), cuya suma podría considerarse también como una utilidad, el importe de estos ahorros o utilidades suma en total 669.30 mdp, una cifra inferior en $374.20 \mathrm{mdp}$ a la

\section{CUADRO 19}

COMPARATIVO DE LA PTU EN AMBAS ALTERNATIVAS (MILES DE PESOS)

\begin{tabular}{|l|c|c|c|c|}
$\begin{array}{l}\text { Periodo operativo } \\
\text { (años) }\end{array}$ & Alternativa "SIN" & Alternativa "CON" & $\begin{array}{c}\text { Diferencia } \\
\text { absoluta }\end{array}$ & $\begin{array}{c}\text { Diferencia } \\
\text { (\%) }\end{array}$ \\
\hline 1 & 828.40 & 861.90 & 33.50 & 3.88 \\
2 & 852.90 & 886.30 & 33.40 & 3.76 \\
3 & 879.70 & 913.20 & 33.50 & 3.67 \\
4 & 909.10 & 942.60 & 33.50 & 3.55 \\
5 & 941.00 & 974.40 & 33.40 & 3.43 \\
\hline
\end{tabular}


utilidad neta generada por la alternativa "CON".

La variabilidad de las utilidades netas, sin embargo, apenas ronda un porcentaje mayor a $3 \%$ y menor a $4 \%$, como puede observarse en el cuadro 20 . Teniendo en cuenta que uno de los rubros más importantes del análisis es la utilidad neta, ¿indicaría eso que no vale la pena hacer la inclusión del IVA en el presupuesto de inversiones? La respuesta no sería concluyente, pues falta ver el resultado de los indicadores de evaluación derivados de los flujos de efectivo de ambas alternativas. Y estos indicadores son más importantes que las propias utilidades netas, ya que son los que se emplean para decidir la aceptación o rechazo de un proyecto.

\subsection{Análisis del estado de fuentes y usos del efectivo}

En efecto, en concordancia con lo dicho en el párrafo anterior, las utilidades netas no permiten conocer totalmente las bondades de un proyecto de inversión debido a que los accionistas no pueden disponer de ellas hasta que no se hayan satisfecho las demandas de efectivo en nuevas inversiones requeridas a lo largo del periodo operativo, así como los pagos de pasivos financieros cuando los haya. Por lo mismo, se requiere analizar otro estado financiero mediante el cual se obtendrá el flujo de efectivo que un proyecto de inversión genera durante el horizonte de planeación del mismo.

Este estado financiero tiene tres componentes principales: el origen o fuente del efectivo, los usos en que se emplea el efectivo y el flujo neto de efectivo que resulta de restar a las fuentes los usos. Este flujo define la capacidad de endeudamiento del proyecto para ver si puede cumplir sus compromisos con accionistas y acreedores. De ningún modo puede ser negativo, pues ello sería indicio de que el proyecto no es capaz de cumplir con sus obligaciones financieras ante socios $\mathrm{o}$ acreedores.

Una mirada al Estado Financiero de cada alternativa (véanse los cuadros 21 y 22) nos lleva a concluir lo siguiente:

1. El flujo de inversiones en el periodo de instalación (año cero) es el mismo en ambas alternativas, aunque su desglose es diferente debido a que la alternativa " $\mathrm{CON}$ " incluye el desglose del IVA, mientras que la alternativa "SIN" no lo incluye.

2. El valor de rescate es diferente en cada alternativa, siendo mayor en el caso de la alternativa "SIN".

3. El flujo neto de efectivo es diferente en cada alternativa; en algunos años es mayor para la alternativa "SIN", mientras que en otros es mayor para la alternativa "CON".

CUADRO 20

COMPARATIVO DE LAS UTILIDADES NETAS EN AMBAS ALTERNATIVAS (MILES DE PESOS)

\begin{tabular}{|l|c|c|c|c|}
$\begin{array}{l}\text { Periodo operativo } \\
\text { (años) }\end{array}$ & Alternativa "SIN" & Alternativa "CON" & $\begin{array}{c}\text { Diferencia } \\
\text { absoluta }\end{array}$ & $\begin{array}{c}\text { Diferencia } \\
\text { (\%) }\end{array}$ \\
\hline 1 & 4970.40 & 5171.20 & 208.80 & 3.88 \\
2 & 5117.20 & 5318.00 & 208.80 & 3.78 \\
3 & 5278.30 & 5479.10 & 208.80 & 3.66 \\
4 & 5454.50 & 5655.50 & 208.80 & 3.55 \\
5 & 5645.90 & 5846.60 & 208.70 & 3.43 \\
\hline
\end{tabular}




\section{CUADRO 21}

ESTADO DE FUENTESY USOS DEL EFECTIVO DE LA ALTERNATIVA “SIN” (MILES DE PESOS)

\begin{tabular}{|c|c|c|c|c|c|c|c|}
\hline Conceptos de efectivo & Año 0 & Año 1 & Año 2 & Año 3 & Año 4 & Año 5 & Año 6 \\
\hline \multicolumn{8}{|l|}{ Fuentes de efectivo } \\
\hline Capital social aportado & 35686.00 & & & & & & \\
\hline Utilidades netas & & 4970.40 & 5117.20 & 5278.30 & 5454.50 & 5645.90 & \\
\hline Gastos virtuales & & 2451.30 & 2451.30 & 2451.30 & 2451.30 & 2451.30 & \\
\hline Valor de rescate & & & & & & 5497.20 & 31101.40 \\
\hline I. Total fuentes de efectivo & 35686.00 & 7421.70 & 7568.60 & 7729.70 & 7905.80 & 13594.40 & 31101.40 \\
\hline \multicolumn{8}{|l|}{ Usos de efectivo } \\
\hline Inversión fija & 21186.00 & & & & 232.00 & 2900.00 & \\
\hline Inversión diferida & 580.00 & & & & & & \\
\hline Capital de trabajo & 13920.00 & & & & & & \\
\hline II. Total de usos del efectivo & 35686.00 & 0.00 & 0.00 & 0.00 & 232.00 & 2900.00 & 0.00 \\
\hline Flujo de efectivo anual & 0.00 & 7421.70 & 7568.60 & 7729.70 & 7673.90 & 10694.40 & 31101.40 \\
\hline
\end{tabular}

CUADRO 22

ESTADO DE FUENTES Y USOS DEL EFECTIVO DE LA ALTERNATIVA “CON” (MILES DE PESOS)

\begin{tabular}{|c|c|c|c|c|c|c|c|}
\hline Conceptos de efectivo & Año 0 & Año 1 & Año 2 & Año 3 & Año 4 & Año 5 & Año 6 \\
\hline \multicolumn{8}{|l|}{ Fuentes de efectivo } \\
\hline Capital social aportado & 35686.00 & & & & & & \\
\hline Utilidades netas & & 5171.20 & 5318.00 & 5479.10 & 5655.30 & 5846.60 & \\
\hline Gastos virtuales & & 2116.70 & 2116.70 & 2116.70 & 2116.70 & 2116.70 & \\
\hline IVA recuperado & & 4456.00 & 72.60 & 75.30 & 110.20 & 481.10 & \\
\hline Valor de rescate & & & & & & 0.00 & 27191.60 \\
\hline I. Total fuentes de efectivo & 35686.00 & 12078.50 & 7841.90 & 8005.70 & 8216.80 & 8779.00 & 27191.60 \\
\hline \multicolumn{8}{|l|}{ Usos de efectivo } \\
\hline Inversión fija & 18730.00 & & & & 200.00 & 2500.00 & \\
\hline Inversión diferida & 500.00 & & & & & & \\
\hline Capital de trabajo & 12000.00 & 0.00 & 453.60 & 470.80 & 488.50 & 507.00 & \\
\hline IVA pagado & 4456.00 & 0.00 & 72.60 & 75.30 & 110.20 & 481.10 & \\
\hline II. Total de usos del efectivo & 35686.00 & 0.00 & 526.20 & 546.10 & 798.70 & 3488.10 & 0.00 \\
\hline Flujo de efectivo anual & 0.00 & 12078.50 & 7315.70 & 7459.60 & 7418.10 & 5290.90 & 27191.60 \\
\hline
\end{tabular}


En resumen, una comparación de los flujos netos de efectivo de cada alternativa nos muestra que los flujos de efectivo de la alternativa "SIN" suman 202.80 mdp más que los de la alternativa "CON", ya que mientras en la primera la suma asciende a $48958.60 \mathrm{mdp}$, en la segunda asciende a 51 161.40 mdp (véase el cuadro 23).

Esta diferencia en la suma total representa una variación de $4.5 \%$, variabilidad que, de acuerdo con el criterio adoptado, implica que no vale la pena hacer la inclusión del IVA.

Estas conclusiones, sin embargo, no permiten tomar una decisión sobre qué alternativa es mejor porque los análisis hechos hasta aquí no tienen en cuenta que el dinero posee un valor en función del tiempo y de una tasa de descuento que incluye tres componentes: un rendimiento real, una tasa de inflación y un premio por el riesgo. Por ello es que terminaremos este documento haciendo uso de indicadores de evaluación de inversiones que sí tienen en cuenta estos parámetros.

\subsection{Análisis del van}

Para llevar a cabo este análisis cabe señalar que los flujos de efectivo de cada alternativa se descontaron teniendo en cuenta que la estructura financiera adoptada para el financiamiento de los activos está integrada exclusivamente por capital social. Por lo mismo, la tasa de descuento empleada equivale al costo de oportunidad que tienen los recursos. Dicho costo de oportunidad o tasa de descuento está formada por tres tasas: la tasa real, la tasa de inflación y un premio por el riesgo.

Sin embargo, dado que todos los cálculos hechos para obtener el flujo neto de efectivo se hicieron a precios constantes, es decir, precios que no incluyen la inflación, a fin de mantener la consistencia en los cálculos

\begin{tabular}{|l|r|r|}
\hline \multicolumn{3}{c}{ CUADRO 23 } \\
\multicolumn{3}{|c|}{$\begin{array}{c}\text { FLUJOS NETOS DE EFECTIVO } \\
\text { (MILES DE PESOS) }\end{array}$} \\
$\begin{array}{l}\text { Horizonte de } \\
\text { planeación } \\
\text { (años) }\end{array}$ & $\begin{array}{c}\text { Alternativa } \\
\text { "SIN" }\end{array}$ & \multicolumn{1}{c}{$\begin{array}{c}\text { Alternativa } \\
\text { "CON" }\end{array}$} \\
\hline 0 & -35686.00 & -35686.00 \\
1 & 7221.70 & 11743.80 \\
2 & 7568.60 & 6981.10 \\
3 & 7729.70 & 7125.00 \\
4 & 6875.20 & 7083.50 \\
5 & 4609.10 & 4956.30 \\
6 & 14954.30 & 13271.70 \\
\hline
\end{tabular}

para hacer la evaluación del proyecto, se excluirá sólo la tasa de inflación. Esto es, una tasa real de $3 \%$ anual y una prima de $5 \%$ anual por el riesgo asumido (véase el Anexo A). Ambas tasas se integraron mediante la siguiente fórmula:

$$
T D=(1+R r)(1+P r)-1
$$

donde $T D=$ Tasa de descuento; $R r=$ Tasa real; $\mathrm{Pr}=$ Prima por riesgo asumido; TD = $(1.03 \times 1.05)-1 ; T D=1.0815-1 ; T D=0.0815$ o $8.15 \%$ anual.

Los cálculos se presentan en los cuadros 24 y 25 , cuyos resultados para cada alternativa se refieren a la cantidad que aparece en la última celda de columna derecha de cada cuadro. En el caso de la alternativa "SIN" el VAN es por $1244.10 \mathrm{mdp}$, mientras que en el caso de la alternativa "CON" es por 3695.50 mdp, una diferencia de 2451.40 mdp a favor de la alternativa "CON", lo que representa una variación de $197 \%$, es decir, casi el doble. Por supuesto que esta variabilidad nos obliga a considerar que la inclusión del IVA debe hacerse. 
CUADRO 24

DETERMINACIÓN DEL VAN DE LA ALTERNATIVA “SIN” (MILES DE PESOS)

\begin{tabular}{|l|r|r|r|r|}
$\begin{array}{l}\text { Horizonte de } \\
\text { planeación (años) }\end{array}$ & $\begin{array}{r}\text { Flujo neto } \\
\text { de efectivo }\end{array}$ & $\begin{array}{c}\text { Tasa de descuento } \\
\text { al 8.153\% }\end{array}$ & $\begin{array}{r}\text { Flujo neto } \\
\text { de efectivo } \\
\text { actualizado }\end{array}$ & $\begin{array}{r}\text { Flujo neto } \\
\text { de efectivo } \\
\text { acumulado }\end{array}$ \\
\hline 0 & -35686.00 & 1.0000 & -35686.00 & -35686.00 \\
1 & 7421.70 & 0.9246 & 6862.40 & -28823.60 \\
2 & 7568.60 & 0.8550 & 6470.80 & -22352.70 \\
3 & 7729.70 & 0.7905 & 6110.50 & -16242.20 \\
4 & 6875.20 & 0.7310 & 5025.50 & -11216.70 \\
5 & 4609.10 & 0.6759 & 3115.20 & -8101.50 \\
\hline 6 & 14954.30 & 0.6249 & 9445.60 & 1244.10 \\
\hline
\end{tabular}

CUADRO 25

DETERMINACIÓN DEL VAN DE LA ALTERNATIVA “CON” (MILES DE PESOS)

\begin{tabular}{|l|r|r|r|r|}
\hline $\begin{array}{l}\text { Horizonte de } \\
\text { planeación (años) }\end{array}$ & $\begin{array}{c}\text { Flujo neto } \\
\text { de efectivo }\end{array}$ & $\begin{array}{c}\text { Tasa de descuento } \\
\text { al 8.15\% }\end{array}$ & $\begin{array}{r}\text { Flujo neto } \\
\text { de efectivo } \\
\text { actualizado }\end{array}$ & $\begin{array}{r}\text { Flujo neto } \\
\text { de efectivo } \\
\text { acumulado }\end{array}$ \\
\hline 0 & -35686.00 & 1.0000 & -35686.00 & -35686.00 \\
\hline 1 & 11743.80 & 0.9246 & 10858.80 & -24727.28 \\
\hline 3 & 6981.10 & 0.8550 & 5968.50 & -18758.80 \\
\hline 4 & 7125.00 & 0.7905 & 5632.50 & -13126.10 \\
\hline 6 & 7083.50 & 0.7310 & 5177.70 & -7948.40 \\
\hline 4956.30 & 0.6759 & 3349.90 & -4598.50 \\
\hline
\end{tabular}

Por otra parte, el que sean positivos ambos indicadores de evaluación sugiere que el proyecto sería aceptado independientemente de la alternativa que se hubiese usado. Ahora bien, de acuerdo con el criterio de aceptación que establece este indicador (el vaN), siempre deben preferirse los proyectos que tengan el mayor valor positivo, en igualdad de condiciones de riesgo y horizonte de planeación. En este caso, la mejor alternativa es la "CON", y teniendo en cuenta que la alternativa "SIN" infringen las leyes fiscales, la conclusión obvia es que es necesario incluir el desglose del IVA en el presupuesto de inversiones.

\subsection{Análisis del PRC}

Este indicador se refiere al periodo de tiempo en el cual se recupera el capital invertido por los socios. Para hacer este análisis se empleó la última columna de los cuadros 24 y 25 , la que dice "Flujo neto de efectivo acumulado".

Para el cálculo del PRC se hizo lo siguiente: las cifras del flujo neto de efectivo actualizado se acumularán en la última columna 
del cuadro 26, notándose que hasta el año 5 estas cantidades son negativas, aunque año con año van dejando de serlo hasta, en algún momento del año 6, volverse positiva.

En este caso se puede observar que en ambas alternativas el flujo neto de efectivo acumulado se torna positivo en el año $6 \mathrm{y}$, por tanto, el PRC se efectúa en poco menos de seis años. En efecto, para la alternativa "SIN" el PRC es de 5.86 años, mientras que para la alternativa "CON" fue de 5.55 años, es decir, apenas 0.31 años (casi cuatro meses) de diferencia, lo que equivale a una variación de $5.59 \%$, apenas superior al criterio establecido, haciendo válida la sugerencia de que es necesario desglosar el IVA.

\subsection{Análisis del coeficiente de beneficio/costo}

Este indicador se obtiene de dividir el van entre la inversión inicial realizada en el periodo cero. El resultado es un coeficiente que indica la rentabilidad por cada peso invertido durante los seis años que dura el proyecto.

CUADRO 26

DETERMINACIÓN DEL PRC

PARA AMBAS ALTERNATIVAS

\begin{tabular}{|c|c|c|}
\hline \multirow{2}{*}{$\begin{array}{l}\text { Horizonte de } \\
\text { planeación } \\
\text { (años) }\end{array}$} & \multicolumn{2}{|c|}{$\begin{array}{l}\text { Flujo neto de } \\
\text { efectivo acumulado }\end{array}$} \\
\hline & $\begin{array}{l}\text { Alternativa } \\
\text { "SIN" }\end{array}$ & $\begin{array}{l}\text { Alternativa } \\
\text { "CON" }\end{array}$ \\
\hline 0 & -35686.00 & -35686.00 \\
\hline 1 & -28823.60 & -24517.80 \\
\hline 2 & -22352.70 & -18263.10 \\
\hline 3 & -16242.20 & -12366.10 \\
\hline 4 & -10632.90 & -6943.70 \\
\hline 5 & -3404.80 & -3367.70 \\
\hline 6 & 16031.80 & 13625.50 \\
\hline PRC & 5.86 años & 5.55 años \\
\hline
\end{tabular}

Es importante señalar que dicho coeficiente no se debe interpretar como una tasa anual de rendimiento, sino como el rendimiento que genera el proyecto durante su horizonte de planeación.

Para hacer el cálculo de este indicador se emplearon los mismos datos del análisis del VAN, derivados de los cuadros 24 y 25 , cuyos resultados se presentan en el cuadro 27; nótese que la alternativa "SIN" genera apenas 3.48 centavos por cada peso invertido, mientras que la alternativa "CON" genera 10.35 centavos por cada peso invertido, es decir, casi triplica el rendimiento de la alternativa "SIN". Lo anterior implica que la variabilidad es de $297 \%$, lo que indica que el desglose del IVA debe ser inminente si se quieren tomar buenas decisiones de inversión.

\subsection{Análisis de la TIR}

Este indicador de evaluación indica la rentabilidad porcentual anual que genera el proyecto, bajo la condición de que los flujos de efectivo se reinviertan a dicha tasa de rendimiento. La TIR también representa una tasa de interés compuesto anual que hace que el vAN de una inversión sea igual a cero, es una especie de punto de equilibrio entre el flujo de inversiones desembolsado durante el horizonte de planeación y el flujo de efectivo que dicho proyecto genera en tal horizonte.

\section{CUADRO 27}

DETERMINACIÓN DEL BENEFICIO/COSTO PARA AMBAS ALTERNATIVAS (MILES DE PESOS)

\begin{tabular}{|l|r|r|} 
Datos & \multicolumn{1}{|c|}{$\begin{array}{c}\text { Alternativa } \\
\text { "SIN" }\end{array}$} & \multicolumn{1}{c|}{$\begin{array}{c}\text { Alternativa } \\
\text { "CON" }\end{array}$} \\
\hline $\begin{array}{l}\text { Inversión } \\
\text { inicial }\end{array}$ & -35686.00 & -35686.00 \\
VAN & 1244.10 & 3695.50 \\
B/C & 0.0348 & 0.1035 \\
\hline
\end{tabular}


CUADRO 28

DETERMINACIÓN DE LA TIR DE LA ALTERNATIVA “SIN” (MILES DE PESOS)

\begin{tabular}{|l|c|c|c|c|c|}
$\begin{array}{l}\text { Horizonte de } \\
\text { planeación } \\
\text { (años) }\end{array}$ & $\begin{array}{c}\text { Flujo neto de } \\
\text { efectivo }\end{array}$ & $\begin{array}{c}\text { Tasa de } \\
\text { descuento } \\
\text { al 9\% }\end{array}$ & $\begin{array}{c}\text { Flujo neto } \\
\text { de efectivo } \\
\text { actualizado }\end{array}$ & $\begin{array}{c}\text { Tasa de } \\
\text { descuento } \\
\text { al } 10 \%\end{array}$ & $\begin{array}{c}\text { Flujo neto } \\
\text { de efectivo } \\
\text { actualizado }\end{array}$ \\
\hline 0 & -35686.00 & 1.0000 & -35686.00 & 1.0000 & -35686.00 \\
1 & 7421.70 & 0.9174 & 6808.90 & 0.8475 & 6289.60 \\
\hline 3 & 7568.60 & 0.8417 & 6370.30 & 0.7182 & 5435.60 \\
\hline 5 & 7729.70 & 0.7722 & 5968.70 & 0.0860 & 4704.50 \\
6 & 6875.20 & 0.7084 & 4870.57 & 0.5158 & 3958.10 \\
\hline
\end{tabular}

En la medida que la tasa de descuento aumenta, el flujo neto de efectivo actualizado decrece, pasando de un valor positivo a llegar a cero y de ahí disminuye en forma negativa. En el caso de la alternativa "SIN", en el cuadro 28 podemos observar que dicha tasa se encuentra entre el $9 \%\left(i_{1}\right)$ y el $10 \%$ $\left(i_{2}\right)$. Dichas tasas se sustituyen en la fórmula y se obtiene una TIR de $9.218 \%$.

El cálculo exacto de la TIR se obtiene mediante el empleo de la siguiente fórmula:

$$
T I R=i_{1}+\frac{\left(i_{2}-i_{1}\right)\left(V A N_{1}\right)}{A B S\left(V A N_{2}-V A N_{1}\right)}
$$

Sustituyendo valores se tiene:

$$
\begin{gathered}
\text { TIR }=9 \%+\frac{(10-9)(244.8)}{A B S(-877.5-244.8)} \\
\text { TIR }=9 \%+\frac{244.8}{1122.3} \\
\text { TIR }=9 \%+0.218 \\
\text { TIR }=9.218 \%
\end{gathered}
$$

$V A N_{1}$ al 9\% $=-244.80 \mathrm{mdp}$ $V A N_{2}$ al $10 \%=-877.50 \mathrm{mdp}$
En el caso de la alternativa "CON", en el cuadro 29 podemos observar que la TIR es muy similar a la de la alternativa "SIN", ya que este rendimiento es de $11.47 \%$ y se encuentra entre las tasas de descuento del $11 \%\left(i_{1}\right)$ y $12 \%\left(i_{2}\right)$.

El cálculo exacto de la TIR se encuentra mediante la siguiente fórmula:

$$
T I R=i_{1}+\frac{\left(i_{2}-i_{1}\right)\left(V A N_{1}\right)}{A B S\left(V A N_{2}-V A N_{1}\right)}
$$

Sustituyendo valores se tiene:

$$
\begin{gathered}
\text { TIR }=11 \%+\frac{(12-11)(472.7)}{A B S(-525.8-472.7)} \\
\text { TIR }=11 \%+\frac{472.7}{998.5} \\
T I R=11 \%+0.47 \% \\
\text { TIR }=11.47 \%
\end{gathered}
$$

$$
\begin{aligned}
V A N_{1} & =472.70 \mathrm{mdp} \\
V A N_{2} & =-525.80 \mathrm{mdp}
\end{aligned}
$$

Así pues, mientras la alternativa "SIN" genera un rendimiento anual de $9.218 \%$, la 
CUADRO 29

DETERMINACIÓN DE LA TIR DE LA ALTERNATIVA “CON” (MILES DE PESOS)

\begin{tabular}{|l|r|r|r|r|r|}
$\begin{array}{l}\text { Horizonte de } \\
\text { planeación } \\
\text { (años) }\end{array}$ & $\begin{array}{c}\text { Flujo neto de } \\
\text { efectivo }\end{array}$ & $\begin{array}{c}\text { Tasa de } \\
\text { descuento } \\
\text { al 11\% }\end{array}$ & $\begin{array}{c}\text { Flujo neto } \\
\text { de efectivo } \\
\text { actualizado }\end{array}$ & $\begin{array}{c}\text { Tasa de } \\
\text { descuento } \\
\text { al 12\% }\end{array}$ & $\begin{array}{c}\text { Flujo neto } \\
\text { de efectivo } \\
\text { actualizado }\end{array}$ \\
\hline 0 & -35686.00 & 1.0000 & -35686.00 & 1.0000 & -35686.00 \\
\hline 1 & 11743.80 & 0.9009 & 10580.00 & 0.8929 & 10485.60 \\
3 & 6981.10 & 0.8116 & 5666.00 & 0.7972 & 5565.30 \\
4 & 7125.00 & 0.7312 & 5209.70 & 0.7118 & 5071.40 \\
5 & 7083.50 & 0.6587 & 4666.10 & 0.6355 & 4501.70 \\
6 & 4956.30 & 0.5935 & 2941.30 & 0.5674 & 2812.30 \\
\hline
\end{tabular}

alternativa “CON" genera uno de $11.47 \%$, lo cual representa una diferencia absoluta de 2.252 puntos pocentuales. Esta diferencia de rendimientos presenta una variabilidad de $24.43 \%$, la cual, para efectos de este análisis, indica que es necesario incluir el desglose del Iva en el presupuesto de inversiones del proyecto.

\section{CONCLUSIONES}

De los diferentes análisis realizados, sólo en los referidos a gastos de operación, punto de equilibrio, ISR, PTU y utilidad neta, la variabilidad fue menor a 5\%, el resto de los temas examinados satisface la hipótesis planteada en el sentido de que la gran mayoría de los aspectos e indicadores financieros del proyecto de inversión sufre una variabilidad superior a 5\%. De acuerdo con la hipótesis planteada, ello implica la conveniencia de incluir el desglose del IVA en el presupuesto de inversiones de un proyecto.

Pero independientemente de la variabilidad que haya entre las dos alternativas analizadas y de a quien favorecen dichas diferencias y variabilidad, podemos decir que la única alternativa correcta y viable es la que se ajusta a los requerimientos fiscales. Por consiguiente, más importante que la variabilidad en los resultados, está el cumplimiento fiscal tanto de los ordenamientos de la Ley del Impuesto al Valor Agregado como los de la Ley del Impuesto Sobre la Renta, pues de no cumplir con el desglose del IVA, los activos no tendrán validez fiscal y, por lo mismo, los gastos inherentes a tales activos, como las depreciaciones y amortizaciones, no serán deducibles del ingreso para fines del cálculo del ISR.

A lo anterior debe añadirse el hecho de que las discrepancias mostradas por los diferentes estados e indicadores financieros llevarán a los tomadores de decisiones a cometer errores en la interpretación de los estados e indicadores financieros, así como en la evaluación y selección de proyectos viables, puesto que muy posiblemente se aceptarán proyectos que en estricto sentido debieran rechazarse y viceversa. $\mathbf{6}$ 


\section{ANEXO A. INFORMACIÓN SOBRE UN PROYECTO DE INVERSIÓN}

\section{A1. Horizonte de planeación del proyecto}

El horizonte de planeación para llevar a cabo la evaluación del proyecto de inversión está constituido de la siguiente manera: un periodo de instalación de nueve meses, uno de producción de cinco años y uno de liquidación de un año.

\section{A2. Aspectos de mercado y comercialización}

\section{A2.1. Producto a comercializar}

Alimento balanceado de engorda para ganado bovino de carne con $11.7 \%$ de proteína digestible, Peletizado (comprimido) y a granel.

\section{A2.2. Área de mercado}

Hermosillo, Sonora, y los municipios circundantes a Hermosillo.

\section{A2.3. Precio de venta para} posicionar el producto

Precio LAB del establo del ganadero, \$5 130 por tonelada, constante durante los cinco años.

\section{A2.4. Pronóstico de ventas (toneladas anuales)}

El pronóstico de ventas se calculará mediante el escenario normal que derive de aplicar la siguiente ecuación de regresión:

$$
Y_{c}=7320(1.0378) x
$$

Origen: 31 de diciembre de 2005 . Coeficiente de determinación: 0.7395 .
Coeficiente de correlación: $85.99 \%$.

Error estándar del pronóstico: 522.5 toneladas anuales.

\begin{tabular}{|l|l|l|l|l|}
\hline AÑ̃ 1 & AÑO 2 & AÑ̃ 3 & AÑ̃ 4 & AÑO 5 \\
\hline 11857 & 12305 & 12770 & 13253 & 13754 \\
\hline
\end{tabular}

\section{A2.5. Políticas de ventas para la comercialización}

La política de ventas consiste en otorgar hasta un $20 \%$ de las ventas a crédito y un plazo de pago de 15 días.

\section{A3. Flujo de inversiones y reinversiones (datos en miles de pesos)}

\section{A3.1. Inversión inicial requerida}

Para el inicio de operaciones se requieren 35 686.00 mdp desglosados como sigue:

INVERSIÓN TOTAL REQUERIDA PARA EL INICIO DE OPERACIONES (MILES DE PESOS)

\begin{tabular}{|l|r|}
\hline Conceptos de inversión & Importe \\
\hline Inversión fija & 21186.00 \\
Terreno & 3380.00 \\
Edificio & 7540.00 \\
Equipo de proceso & 6264.00 \\
Equipo de transporte & 2900.00 \\
Equipo de computo & 232.00 \\
Equipo de oficina & 174.00 \\
Equipo de laboratorio & 696.00 \\
Inversión diferida & 580.00 \\
Capital de trabajo & 13920.00 \\
Inversión total inicial & 35686.00 \\
\hline
\end{tabular}

Durante el periodo operativo será necesario reemplazar todos los activos fijos cuya vida útil sea menor que el periodo operativo (equipos de 
cómputo y transporte); asimismo, el capital de trabajo variará en función de la tasa de crecimiento del pronóstico de venta.

Por su parte, en el periodo de liquidación (año 6) se desinvierte enajenando todos los activos de acuerdo con su valor en libros; las cifras o importes obtenidos por estas desinversiones representan una entrada de efectivo y el signo de ésta será positivo, a diferencia de las demás cifras que hay en los periodos de instalación y operación.

En el cuadro 3 se puede observar que las reinversiones requeridas durante los cinco años de operación del proyecto se incrementan año con año, pasando de $472.50 \mathrm{mdp}$ en el segundo año a 3428.20 mdp en el último año de operación, siendo el valor máximo a alcanzar.

\section{A3.2. Flujo de reinversión durante el periodo operativo}

Las reinversiones requeridas durante los cinco años de operación del proyecto se incrementan año con año, pasando de $526.20 \mathrm{mdp}$ en el segundo año a $3488.10 \mathrm{mdp}$ en el último año de operación, el valor máximo a alcanzar, de acuerdo con el siguiente cuadro: de operación incluyen los diversos conceptos asociados a las funciones sustantivas de la empresa, esto es, a la fabricación de los bienes y servicios, a la administración de las operaciones y a la comercialización de los bienes y servicios producidos. Al igual que los precios e inversiones y reinversiones, los egresos se calculan a precios constantes.

\section{A4.1. Costos directos}

Los conceptos de costo directo se refieren a las materias primas, la mano de obra a destajo, la energía eléctrica, las mermas derivadas del proceso productivo y las comisiones por venta pagadas a los comisionistas o vendedores. La suma de estos conceptos representa el 32.5\% del precio de venta.

\section{A4.2. Gastos de operación}

Los gastos de operación se agruparon en dos grandes rubros: 1) los gastos que se erogan en efectivo en las actividades de fabricación, comercialización y administración y 2) los gastos virtuales referidos a las depreciaciones y amortizaciones de los activos.

\section{FLUJO DE REINVERSIÓN}

\begin{tabular}{|l|c|c|c|c|}
\hline Conceptos & Año 2 & Año 3 & Año 4 & Año 5 \\
\hline Equipo de cómputo & & & 232.00 & \\
Equipo de transporte & & & & \\
Capital de trabajo & 526.20 & 546.10 & 566.70 & 588.10 \\
Reinversión total & 526.20 & 546.10 & 798.70 & 3488.10 \\
\hline
\end{tabular}

\section{A4. Egresos durante el periodo operativo}

Los egresos se refieren a los costos directos y a los gastos de operación requeridos durante los cinco años que operará el proyecto. Los gastos
Los gastos erogables son más o menos fijos, aunque pueden variar en función de la actividad señalada por el pronóstico de ventas y no todos los conceptos variarán ni lo harán de la misma manera, tal como puede apreciarse detalladamente en el siguiente cuadro: 


\begin{tabular}{|l|r|r|}
\hline Conceptos de gasto & $\begin{array}{c}\text { Para producir } \mathbf{1 0} \text { mil } \\
\text { toneladas anuales }\end{array}$ & $\begin{array}{c}\text { Producción de } \mathbf{5 0 0} \text { toneladas } \\
\text { anuales adicionales }\end{array}$ \\
\hline Sueldos, salarios y honorarios ${ }^{1 /}$ & 3896270.00 & 357725.00 \\
Combustibles y lubricantes $^{2 /}$ & 129350.00 & 9315.00 \\
Energéticos $^{3 /}$ & 67890.00 & 6465.00 \\
Agua potable y aditivos para agua & 6000.00 & 90.00 \\
Mantenimiento preventivo & 76250.00 & 7260.00 \\
Mantenimiento correctivo & 12100.00 & 1145.00 \\
Seguros diversos para riesgos & 45890.00 & 0.00 \\
Gastos generales ${ }^{4 /}$ de fabricación & 6500.00 & 0.00 \\
Teléfono, fax, télex y correo & 9500.00 & 0.00 \\
Gastos generales de administración & 1750.00 & 0.00 \\
Fletes, acarreos y paquetería & 10000.00 & 200.00 \\
Teléfono, fax, télex, correo & 15000.00 & 100.00 \\
Viáticos y representación & 23000.00 & 200.00 \\
Seguros diversos para riesgos & 29000.00 & 0.00 \\
Gastos generales de ventas & 6000.00 & 0.00 \\
Gasto erogable total anual & 4334500.00 & 382500.00 \\
\hline
\end{tabular}

Notas:

1/ Este rubro incluye el $40 \%$ de gastos de previsión social como: aguinaldo, prima de vacaciones, Infonavit (Instituto del Fondo Nacional de la Vivienda para los Trabajadores), IMSS (Instituto Mexicano del Seguro Social), SAR (Sistema de Ahorro para el Retiro) e impuestos sobre nóminas.

2/ Este renglón engloba a la gasolina, Diésel y diversos tipos de aceites y grasas.

$3 /$ Incluye energía eléctrica, gas natural y cualesquiera otros tipos de energéticos no mencionados.

4/ Incluye aquellos gastos que por ser pequeños no se contemplan individualmente, tales como: papelería, mensajería, estopas, limpiadores, detergentes, jabones, agua, etcétera.

Para el caso que nos ocupa, el gasto erogable se calculó para una producción modular base de 10 mil toneladas anuales, así como para incrementos anuales que se den por cada 500 toneladas adicionales a la producción base.

En el caso de los gastos virtuales es necesario recurrir a la Ley del Impuesto Sobre la Renta para determinar qué porcentajes de depreciación se deben aplicar a los distintos conceptos de inversión requeridos por el proyecto.

\section{A5. Estructura financiera adoptada para el financiamiento del proyecto}

Dado que la estructura financiera tiene implicaciones sobre la determinación de los flujos de efectivo y la tasa de descuento, y dado que el propósito de este caso no tiene qué ver con dicho tema, se consideró que la forma de financiamiento de los activos de este proyecto se hará exclusivamente mediante capital social, emitiendo acciones a $\$ 5$ por acción.

\section{A6. Tasa de descuento}

La tasa de descuento considerada para realizar la evaluación del proyecto considera una tasa real de $3 \%$ y un premio por el riesgo de $5 \%$, es decir: $\mathrm{TD}=(1.03) \times(1.05)-1=8.15 \%$ real . 